\title{
Transcriptome and metabolome analysis in shoot and root of Valeriana fauriei
}

\author{
Yun Ji Park', Xiaohua Li ${ }^{1}$, Seung Jae Noh², Jae Kwang Kim³ ${ }^{3}$, Soon Sung Lim ${ }^{4}$, Nam II Park ${ }^{5}$, Soonok Kim , \\ Yeon Bok Kim , Young Ock Kim7, Sang Won Lee ${ }^{7}$, Mariadhas Valan Arasu, Naif Abdullah Al-Dhabi ${ }^{8}$ \\ and Sang Un Park ${ }^{*}$
}

\begin{abstract}
Background: Valeriana fauriei is commonly used in the treatment of cardiovascular diseases in many countries. Several constituents with various pharmacological properties are present in the roots of Valeriana species. Although many researches on $V$. fauriei have been done since a long time, further studies in the discipline make a limit due to inadequate genomic information. Hence, Illumina HiSeq 2500 system was conducted to obtain the transcriptome data from shoot and root of $V$. fauriei.

Results: A total of 97,595 unigenes were noticed from 346,771,454 raw reads after preprocessing and assembly. Of these, 47,760 unigens were annotated with Uniprot BLAST hits and mapped to COG, GO and KEGG pathway. Also, 70,013 and 88,827 transcripts were expressed in root and shoot of $V$. fauriei, respectively. Among the secondary metabolite biosynthesis, terpenoid backbone and phenylpropanoid biosynthesis were large groups, where transcripts was involved. To characterize the molecular basis of terpenoid, carotenoid, and phenylpropanoid biosynthesis, the levels of transcription were determined by qRT-PCR. Also, secondary metabolites content were measured using GC/MS and HPLC analysis for that gene expression correlated with its accumulation respectively between shoot and root of $V$. fauriei.

Conclusions: We have identified the transcriptome using Illumina HiSeq system in shoot and root of $V$. fauriei. Also, we have demonstrated gene expressions associated with secondary metabolism such as terpenoid, carotenoid, and phenylpropanoid.
\end{abstract}

Keywords: Valeriana fauriei, Illumina HiSeq system, Digital gene expression, Terpenoid, Carotenoid, Phenylpropanoid

\section{Background}

The genus Valeriana, containing over 250 species grown in Europe, Britain, and Asia [1,2]. The roots of Valeriana plants are used mainly for medicinal purposes. The roots have been known to contain several photochemical constituents with pharmacological properties including hypnotic, sedative, antispasmodic, mild anodyne, hypotensive and carminative effects [3]. Among them, Valeriana fauriei, which is found widely in the northeast of China, South Korea, and Japan, has been used in folks for hundreds of years (Fig. 1) [4]. Researchers have

\footnotetext{
*Correspondence: supark@cnu.ac.kr

'Department of Crop Science, Chungnam National University, 99 Daehak-ro, Yuseong-gu, Daejeon 305-764, Korea

Full list of author information is available at the end of the article
}

isolated more than 150 compounds from Valeriana plants, such as monoterpenes, sesquiterpenes, iridoids, alkaloids, and so on [5]. It has been reported that flavonoids and alkaloids are primarily observed in the aerial parts and sesquiterpenes and iridoids noticed in rhizomes and roots [6, 7]. Among these constituents, valerenic acid is responsible for the sedative effects and its derivatives are produced in roots and rhizomes as principal compounds of Valeriana species [8,9].

Terpenes, one of the major secondary metabolites in medicinal plants, have many volatile representatives such as isoprenes (C5), monoterpenes (C10), sesquiterpenes (C15), even some diterpenes (C20), and triterepenes (C30) [10]. Members of this family serve many important functions like protecting the plants from many 
insects, pest, herbivores and microbial pathogens such as bacteria and fungi [11]. All terpenes are assembled from the basic unit of isoprenes, isopentenyl diphosphate (IPP) and dimethylallyl diphosphate (DMAPP). These universal five carbon precursors are derived from two alternate biosynthetic pathways: mevalonate (MVA) pathway from acetyl-CoA and the 2-C-methylerythritol 4-phosphate (MEP) pathway from glycerol and pyruvate (Additional file 1) [12]. Recent report claimed that even though the operation of this pathway is independent, some metabolic connection were observed between the two pathways [13].

The MVA pathway initiates with the formation of acetoacetyl-CoA by acetocetyl-CoA thiolase $(A A C T)$. The HMG-CoA synthase (HMGS) catalyzes the synthesis of 3-hydroxy-3-methylglutaryl-CoA with one acetylCoA and one acetoacetyl-CoA. Next, HMG-CoA reductase (HMGR) synthesizes the MVA. Further, enzymes such as mevalonate kinase $(M K)$, phosphomevalonate kinase $(P M K)$, and mevalonate diphosphate decarboxylase $(M V D)$ catalyze the formation of IPP. The first step in MEP pathway, pyruvate and glyceraldehyde3-phosphate combined and produce 1-deoxy-D-xylulose 5-phosphate by DOXP synthase (DXS) which is mainly observed in plastids. Then, the conversion of 1-deoxy-Dxylulose-5-phosphate to 2-C-methyl-D-erythritol 4-phosphate is carried out by DOXP reductoisomerase (DXR). MEP is transformed into 1-hydroxy-2-methyl-2(E)-butenyl 4-phosphate by the action of various catalytic enzymes. Enzyme (E)-4-hydroxy-3-methylbut 2-enyl diphosphate reductase $(H D R)$ catalyzes the synthesis of IPP and DMAPP [12]. IPP and DMAPP are formed by the action of enzymes geranyl diphosphate synthase (GPS) and farnesyl diphosphate synthase (FPS), respectively [10]. IPP and DMAPP are the backbone for the synthesis of all terpenes.

Carotenoids, the natural C40 isoprenoid products, are essential hydrophobic plant compounds which contribute to yellow, orange or red color [14]. Carotenoids play an important role in photosynthesis, photomorphogenesis, and photoprotection. It is also mainly involved in the production of abscisic acid. The main carotenoid biosynthetic pathway was identified in many plants and studied extensively. The pathway begins with condensation of 3 molecules of geranyl-geranylpyrophosphate, a precursors from the upstream MEP pathway for production of 15-cis-phytoene catalyzed by phytoene synthase (PSY) (Additional file 2) [15]. Then, 15-cis-phytoene is converted to lycopene, the first yellow carotenoid, through desaturation reactions which are synthesized by both phytoene desaturase (PDS) and $\zeta$-carotene desaturase $(Z D S)$ [16]. Poly-cis lycopene to trans-lycopene is produced by the action of carotenoid isomerase ( $\mathrm{CrtISO}$ ) [17]. Next, carotenoid biosynthesis is branched to produce $\alpha$ - and $\beta$-carotene by enzymatic catalytic activity of two lycopene cyclases, lycopene $\beta$-cyclase $(L C Y B)$ and lycopene $\varepsilon$-cyclase $(L C Y E)$ [18]. $\alpha$-carotene is hydroxylated into lutein by both $\beta$-ring hydroxylase $(C H X B)$ and $\varepsilon$-ring hydroxylase $(C H X E)$. In the other bransch, $\beta$-carotene is transformed into zeaxanthin; process is catalyzed by CHXB. Next, zeaxanthin epoxidase $(Z E P)$ allows synthesis of violaxanthin from zeaxanthin. At last, the enzymatic activity of nine-cisepoxycarotenoid dioxygenases (NCEDs) is responsible for the synthesis of abscisic acid as the final product [17]. Along the pathway, the oxidative activity of the specific enzymes generate apocarotenoids which is further degraded by carotenoid cleavage dioxygenases (CCDs) [19].

Phenolic compounds, widely distributed in higher plants, belong to one of the major classes of secondary metabolites including lignins, flavonols, isoflavonoids and anthocyanins [20]. These compounds contribute many important functional aspects of plant life such as UV sunscreens, pigments signaling. Additionally, accumulation of phenolic compounds is stimulated by biotic and abiotic responses. Currently, many researchers have been focused on the improvement of phenolic compounds in plants, because of its health promoting properties and curing properties to cancers, neurodegenerative diseases, cardiovascular diseases, osteoporosis and diabetes respectively [21]. Phenolic compounds are synthesized through the phenylpropanoid pathway and its biosynthesis starts with the condensation of the phenylalanine which is end product of shikimate pathway (Additional file 3). In the first step, deamination reaction involved by the action of phenylalanine ammonia-lyase $(P A L)$ for the generation of trans-cinnamic acid [22]. Next, cinnamate 4-hydroxylase $(\mathrm{C} 4 \mathrm{H})$ and 4-coumaroyl CoA ligase $(4 \mathrm{CL})$ involved in the production of other intermediate metabolites [20]. In several side branches, $p$-coumarate acid 3-hydroxylase $(\mathrm{C} 3 \mathrm{H})$ converts $p$-coumaric acid to caffeic acid which is transformed to ferulic acid, carried out by the enzyme caffeate O-mehtyltransferase (COMT) [22]. Also, the enzyme hydroxycinnamoyl-CoA quinate hydroxyl cinnamoyl transferase $(H Q T)$ is involved in synthesis of $p$-coumaroylquinate from $\mathrm{p}$-coumaroyl $\mathrm{CoA}$ which is then converted to chlorogenic acid by $\mathrm{C} 3 H$ [21]. Finally, chalcone synthase $(C H S)$, catalyzes naringenin-chalcone, which is the derivative of the flavanoids. In downstream steps, various enzymes such as isomerases, reductases, and hydroxylases involved in the alternation of the basic flavonoid skeleton, leading to the different flavonoid subclasses [23].

Recently, whole transcriptome sequencing using nextgeneration sequencing (NGS) technologies, or RNA sequencing (RNA-Seq) has been widely used for the characterization of genes and their functions in secondary metabolite synthesis [24]. NGS technologies have 
efficiency due to its much higher levels of sensitivity, accuracy, dymamic-range of gene expression levels and fast run times (ranging from hours to days) compared to traditional low-throughput expressed sequence tag (EST) sequencing by Sanger technology [25, 26]. Also, many information such as quantitative gene expression, development of functional markets, quick insights into the specific gene space, comparative genomic studies and to isolate genes of interest [27, 28]. Among the common NGS platforms, including Illumina, Roche/454, SOLiD, and HelicosHeliScope, the Illumina HiSeq system has been commonly used because of its high throughput sequencing capacity which results in providing a higher coverage and low costs [29]. Despite these advantages, the sequence reads provide sufficient for de novo assemblies of full-length transcripts, except in the case of small classes of RNA [30]. For Valeriana family, only one transcriptome analysis from the Valeriana officinalis have been described in medicinal plant genomics resource (www.medicinalplantgenomics.msu.edu), whereas the transcriptome analysis of $V$. fauriei has not been investigated yet.

In this current study, we used the IlluminalHiSeq ${ }^{\text {Tm }}$ 2500 system to obtain the transcriptome in shoot and root of $V$. fauriei. We present data confirming that new sequencing technology can provide numerous insights into the molecular arrangement of secondary metabolite biosynthesis. In addition, we describe the identification of several full-length and partial-length cDNAs encoding genes related to terpenoid, carotenoid, and phenylpropanoid biosynthetic pathways. The transcripts levels of all genes were determined by real-time PCR and quantify the secondary metabolites with high-performance liquid chromatography (HPLC) to investigate the correlation between the transcriptional regulation of each biosynthetic gene and accumulation of each identified components. Till today no information has been provided the transcriptome characterization of $V$. fauriei.

\section{Results and discussion}

\section{Sequencing and transcriptome assembly}

cDNAs prepared from root and shoot of $V$. fauriei were sequenced using Illumina Hiseq platform. As a result of sequencing, 346,771,454 raw reads were obtained from both samples (Table 1). Initially, total sequences were subjected to preprocessing, resulting in 291,047,351 (83.9 \%) clean reads with $28,761,361,637$ (82.1\%) total base. Preprocessed sequences were taken for de novo transcriptome assembly using CLC Assembly Cell software. In total, 22 different assemblies were generated and the each assembled contig set was qualified with the reference mapping as described in method section. Among those, assembly with word size 63 was selected as the best with respect to mapping result. In total, $23,797,128,049$ (82.7 \%) bases were mapped with coverage of 339.2 to the best assembled set with 143,401 contigs $(70,145,151$ bases). After redundancy removal by CAP3 assembly, 97,595 (61,543,817 bases) unique sequences were obtained ranging from 200 to 15,155 with an average length of 628.2 bases which were considered as a reference transcriptome for $V$. fauriei (Fig. 2a).

\section{Functional annotation}

Final draft transcriptome was subjected to functional annotations by BLASTX mapping against to plant UniProt databases to obtain the biological terms with E-value cutoff 1e-5 (Table 2). Totally, 47,760 (48.7\%) sequences were matched with at least one biological term among UniProt sequence description, gene ontology (GO) KEGG pathway, or COG information. Among annotated, 4099 (4.1\%) sequences were completely obtained the biological term from all databases and the sequences annotated from individual database were 38,849 (39.6 \%) sequences with GO terms, 16,532 (16.8\%) with COG, 7401 (7.1 \%) with KEGG pathway respectively.

Among them, 18,234 (18.6\%) sequences were obtained with the e-value in the range of 0 to $1 e-60$, and $16,426(16.8 \%)$ sequences were with $\geq 70 \%$ similarity (Fig. 2b and c). Also, more than a half of mapped $V$. fauriei transcripts shared annotation information from the three major plant species, i.e. Vitis vinifera, Solanum tuberosum, and Populustricho carpa (Fig. 2d). GO annotations were classified into three subcategories i.e. biological process (BP), molecular functions (MF), and cellular component (CC) (Fig. 3). In the cellular component cluster, cells, cell parts, and organelles were shown to be the top 3 clusters. Among the cluster of molecular functions, binding and catalytic activities were dominant.

Table 1 Summary of the transcriptome assembly of $V$. fauriei

\begin{tabular}{|c|c|c|c|c|c|}
\hline \multicolumn{6}{|l|}{ Sequences } \\
\hline & Reads & Bases & AvgLen (bp) & MinLen (bp) & MaxLen (bp) \\
\hline Raw Sequences & $346,771,454(100 \%)$ & $35,023,916,854$ (100 \%) & 101 & 101.0 & 101 \\
\hline Processed Reads & 291,047,352 (83.9 \%) & $28,761,361,637$ (82.1%) & 98.7 & 90.0 & 101 \\
\hline \multicolumn{6}{|l|}{ Assembly } \\
\hline Assembled Contigs & $143,401(100 \%)$ & $70,145,151(100 \%)$ & 489.1 & 200.0 & 15,155 \\
\hline Unigenes & 97,959 (68.3\%) & $61,543,817(87.7 \%)$ & 628.2 & 200.0 & 15,155 \\
\hline
\end{tabular}




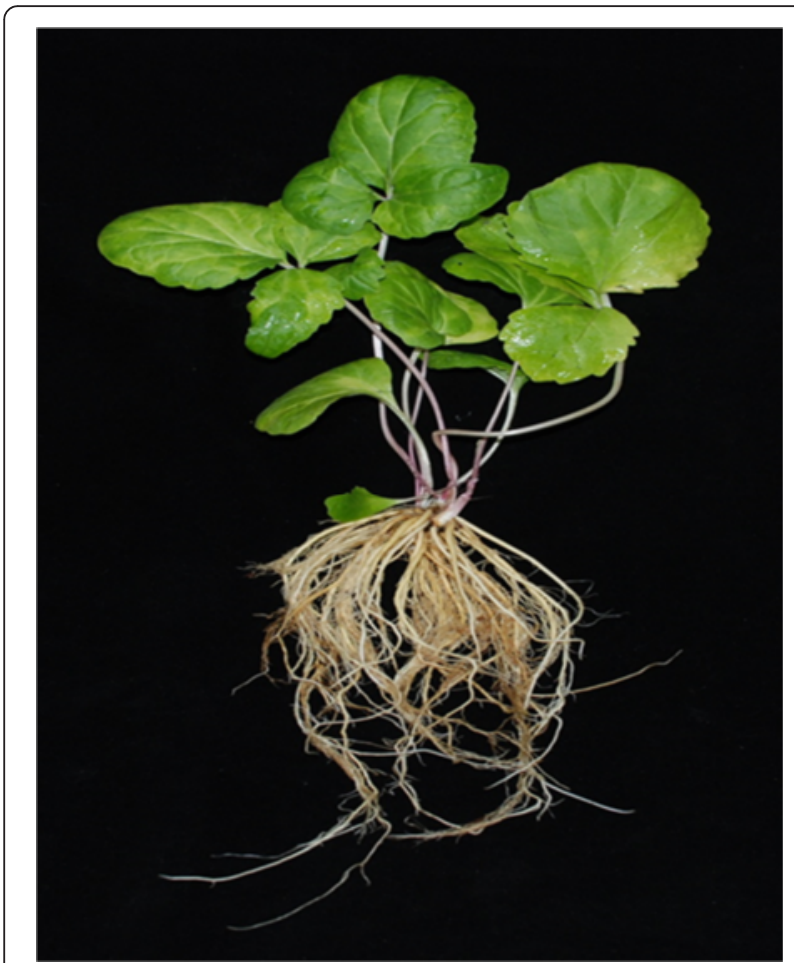

Fig. 1 Photograph of 2-month-old seedling of $V$. fauriei

In the biological process groups, cellular process, metabolic process, and response to stimulus were the largest subcategories. To further characterize the $V$. fauriei transcriptome, sequences were grouped based on MIPS functional categories (Fig. 4). The data comparison enabled the classification of 24 molecular families; the top category was "General function prediction only". Also, the result shows that only $3 \%$ of sequences belong to secondary metabolite biosynthesis, transport, and catabolism.

Transcriptome is the full set of transcripts including mRNAs, non-coding RNAs, and small RNAs and their quantity for a specific developmental stage or physiological conditions. Transcriptome profiling is widely performed for clarifying all species of transcripts, confirming the transcriptional structure of genes, and quantifying the changing expression levels of each transcript during development and under different conditions [31]. The development of next-generation sequencing (NGS) technology for whole transcriptome sequencing has offered highthroughput, advances in accuracy and sensitivity and decreased costs compared to traditional EST sequencing by Sanger technology [32]. The improvements in genome sequencing technology have provided a valuable opportunity to sequence increasingly large and complex genome [33]. Large scale sequencing of several non-model plants which are potential to investigate the basis of medicinal properties has been already assessed to several species i.e., Acacia auriculiformis, Acacia mangium [34], Cajanus cajan L. [35], Euphorbia fischeriana [36], Myricarubra [37], and so on. Although this technology has been extensively practiced to various research areas, genomic information of $V$. fauriei is still unknown. Therefore, transcriptome profiling using NGS from non-model plants is useful to generate a reference genome and to provide the basis of finding genes associated with particular important functions [38].

\section{Digital gene expression and Secondary metabolite related} gene

To analyze the expression profiling of $V$. fauriei transcriptome from root and shoot, all the transcripts were subjected to digital gene expression (DGE) study. First, RPKM values were calculated for each transcript from individual sample. The transcripts with $R P K M \geq 0.3$ were considered as being expressed based on previous published information [39]. Root and shoot specific expressions for all combinations within group were plotted in Venn diagram (Fig. 5). Totally, 91,704 (93.6 \%) unique transcripts were expressed at least single condition. For individual samples, 70,013 (71.5 \%) transcripts and 88,827 (90.7\%) transcripts were expressed in root and shoot, respectively. Among them, 67,136 (68.5 \%) transcripts were commonly shown in both root and shoot of $V$. fauriei. Further, expressed transcripts were grouped into more than 2-fold up- or down-regulations (Table 3).

Between the shoot and root libraries, a total of 45,895 DGEs were detected with 39,145 up-regulated genes (higher expression in root) and 6750 down-regulated genes. To better understand the biological functions of the both organ specific transcripts, DGEs were grouped according to KEGG secondary metabolite biosynthesis pathway (Table 4). Results shows that the terpenoids backbone pathway genes and phenylpropanoid related genes were highly upregulated.

Currently, several tools have developed to analyze the gene expression. Especially, digital gene expression (DGE) is getting popular due to its enrichment for a pathway or ontology term by using overlap statistics from variations in the counts of their cognate sequence tags $[40,41]$. However, DGE requires a reference sequence to align the relative small read lengths [32]. Indeed, performing DGE and RNA-Seq, which provides reference transcriptome, offers an efficient method to identify the candidate genes encoding enzymes involved in the biosynthesis of secondary metabolites in nonmodel plants [42].

\section{Analysis of secondary metabolite biosynthetic genes from $V$. fauriei unigenes}

The sequences of secondary metabolite biosynthetic pathway genes were identified in the NGS of the $V$. fauriei database. Several full-length cDNAs encoding $M C T$, 


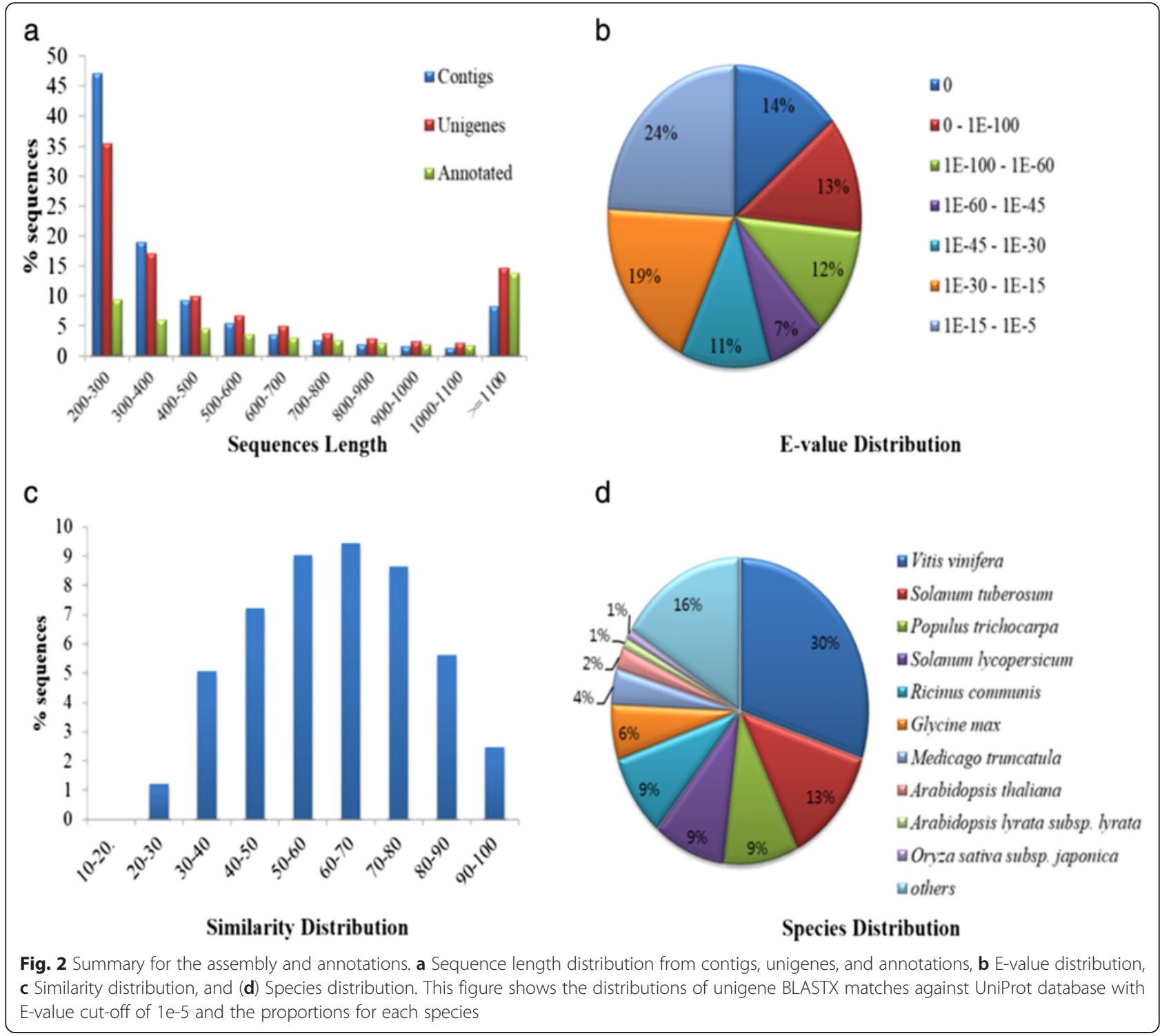

Table 2 Summary of the annotations of the $V$. fauriei transcriptome; GO, Gene Onthology; COG, Cluster Orthologous Groups; KEGG pathway, Kyoto Encyclopedia of Genes and Genomes

\begin{tabular}{lll}
\hline Descriptions & Database Ref IDs & No. Sequences \\
\hline Total Unigenes & - & $97,959(100 \%)$ \\
Annotated with Uniprot BLAST hits & 33,245 & $47,760(48.7 \%)$ \\
Annotated with GO & 4908 & $38,849(39.6 \%)$ \\
Annotated with COG & 1479 & $16,532(16.8 \%)$ \\
Annotated with KEGG & 127 & $7041(7.1 \%)$ \\
Un- annotated & - & $50,199(51.3 \%)$ \\
\hline
\end{tabular}

HDS, GDS, AACT, HMGS, MK, PMK, IDI, and FDS, and partial-length cDNAs encoding $D X S, D X R, C M K, M D S$, $H D R$, and $M V D$ were isolated from $V$. fauriei in terpenoid biosynthesis (Additional file 4). To confirm this for homology, they were designed as VfDXS (489 aa), VfDXR (473 аa), VfMCT (307 aа), VfCMK (310 aа), VfMDS (222 aа), VfHDS (734 аa), VfHDR (446 аa), VfGDS (418 аa), VfAACT (406 aа), VfHMGS (464 aa), VfHMGR (582 aа), VfMK (389 aа), VfCMK (497 aа), VfMVD (417 aа), VfIDI (235 aa), and VfFDS (345 aa) and showed sequence similarities according to BLAST search. Additional file 5 shows the sequences of carotenoid and phenylpropanoid biosynthetic genes identified from NGS data of $V$. faur$i e i$. Among carotenoid biosynthetic genes, full-length cDNAs of VfPDS (569 aa), VfZDS (579 aa), VfCHXB (251 aa), and VfNCED (577 aa), and partial-length cDNAs of VfPSY (347 aа), VfCrtISO (401 aa), VfLCYB (363 аa), 


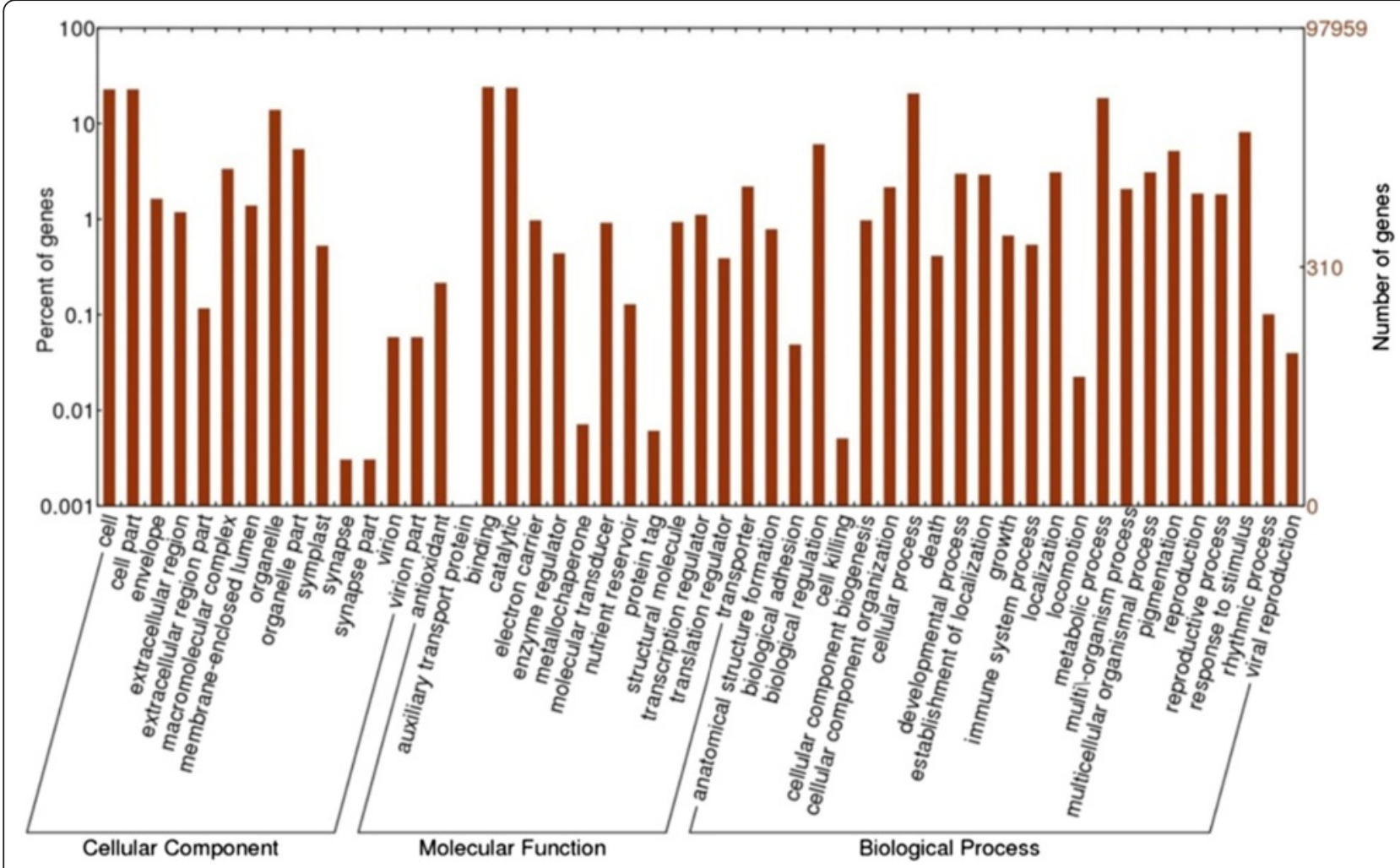

Fig. 3 Transcripts grouped to GO subcategories; biological process (BP), molecular functions (MF) and cellular components (CC) with WEGO software. 38,849 unigenes (39.6\% of total) were annotated and the significant GO were plotted in level 1 and 2

$\operatorname{VfLCYE~(249~aa),~VfCHXE~(403~aa),~VfZEP~(649~aa),~and~}$ $V f C C D(107$ aa) were also exhibited. Additionally, fulllength cDNAs of VfCOMT (240 aa), VfCHS (410 aa), VfF3H (353 aa), VfF3'H (326 aa), and VfFLS (332 aa) and partial-length cDNAs of VfPAL (468 aa), $V f C 4 H$ (407 aa), Vf4CL (406 aа), VfC3H (373 aa), VfHQT (191 aa), VfCHI (172 aа), VfF3'5'H (172 aа), VfFNS (143 aa), VfFNS2 (333 aa), VfGT (175 aa), and VfRT (99 aa) for phenylpropanoid biosynthesis were purified from $V$. fauriei. A BLAST search at the amino acid level showed that secondary metabolite biosynthetic genes from $V$. fauriei exhibited high identity to other orthologous genes.

\section{Analysis of terpenoid transcript levels and terpenoid content}

Quantitative real-time PCR analysis was performed to determine the expression levels of terpenoid biosynthetic genes in shoot and root of $V$. fauiriei (Fig. 6). Most of genes which are related to MEP pathway were expressed at the higher level in root than in shoot of $V$. fauriei. However, expression levels of VfDXR and VfMDS were about 2.23-, 1.17-fold higher in shoot than in root of $V$. fauriei respectively. In contrast, all MVA biosynthetic genes showed a minimum of 1.29- to a maximum of 13.88-fold higher levels in root than in shoot of $V$. fauriei. About 130 volatile compounds were detected in $V$. fauriei by GC and GC/MS analysis. All the reported volatile compounds including terpenes are presented in the Additional files 6 and 7. Among the total volatile compounds, there have been 54 terpenes; 17 monoterpenes, 34 sesquiterpenes, and 3 other terpenes isolated from $V$. fauriei. The results showed that bornyl acetate (13, $24.828 \%)$, cedrol (37, $5.687 \%)$, and $\alpha$-acrorenol (41, $5.185 \%)$ are the major constituents in root whereas p-cymene $(5,10.879 \%)$ and pentanoic acid (52, 5.564 \%) are principal constituents in shoot of $V$. fauriei. Isovaleric acid (53), causing an unpleasant odor, was detected only in the root. HPLC analysis was also done to detect three types of valerenic acid i.e., valerenic acid, acetoxyvalerenic acid, and hydroxyvalerenic acid in both shoot and root of $V$. fauriei (Table 5). The accumulation of valerenic acid and acetoxy-valerenic acid were detected only in root of $V$. fauriei, exhibiting the concentrations of $219.09 \mu \mathrm{g} / \mathrm{g}$ dry weight, $32.22 \mu \mathrm{g} / \mathrm{g}$ dry weights, respectively. However, hydroxyvalerenic acid was not present in the analysis of both shoot and root of this plant.

Until now, most of the studies have focused on root part of Valeriana species, whereas aerial part has been studied very rarely. Leaf contained valeric acid-related compounds as the major compounds [43]. In addition, patchouli alcohol, $\alpha$-pinene, and $\beta$-pinene were shown 


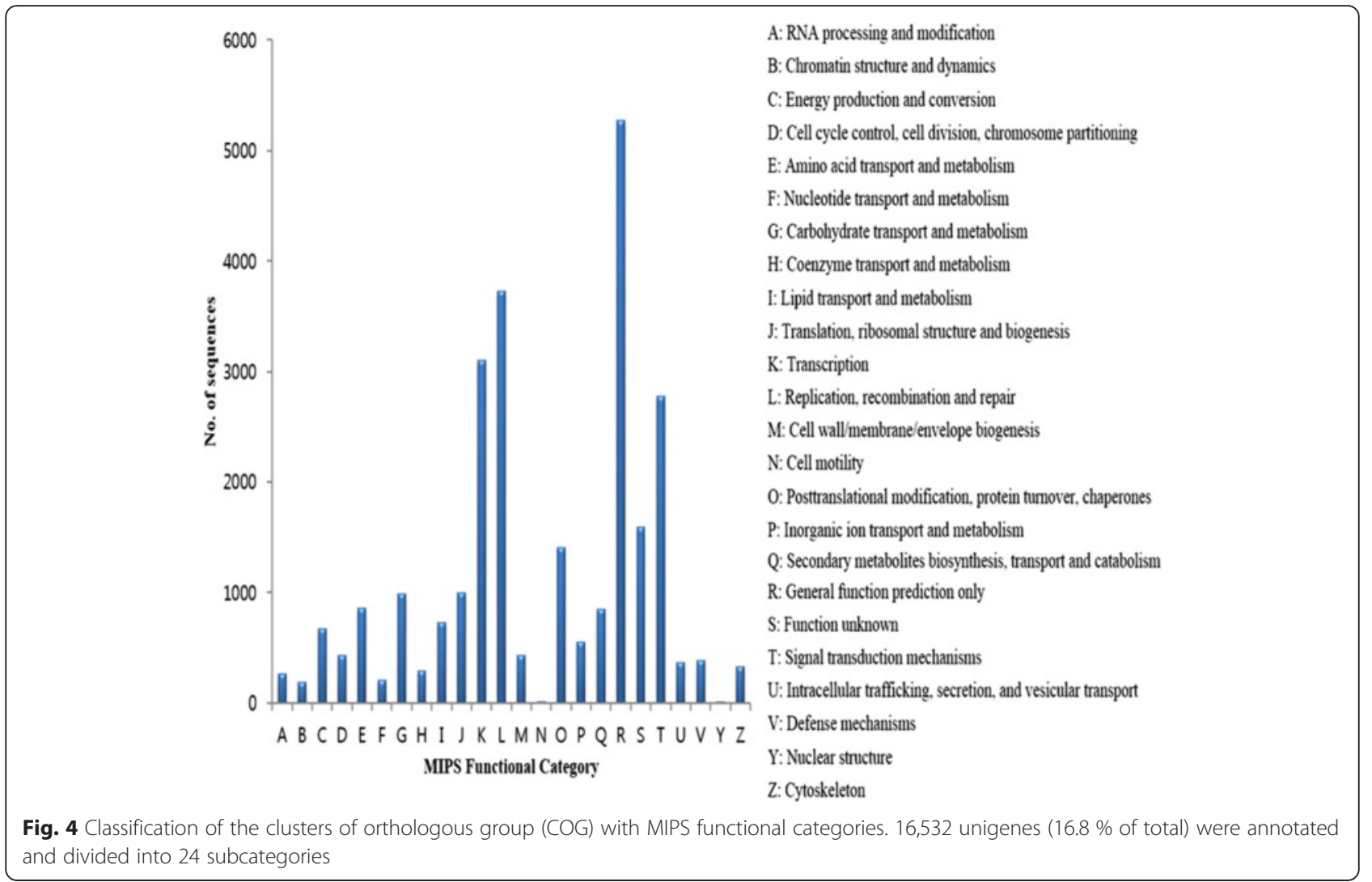

mainly in the oil of aerial parts of $V$. dioschoridis. Patchouli alcohol and isovaleric acid contributed major level of oil in the aerial parts of $V$. celtica [44, 45]. According to our study, p-cymene and pentanoic acid were detected as major compounds, whereas bornyl isovalerate

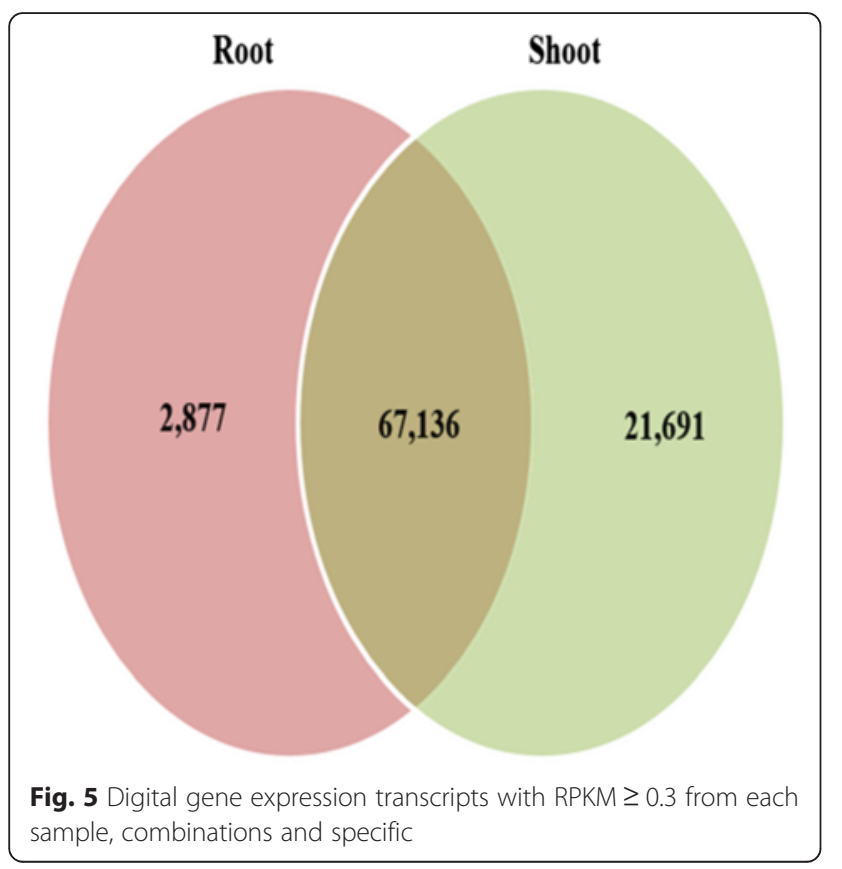

is present as a little amount in shoot of $V$. fauriei. The major active compounds present in Valeriana species such as valerenic acid and its derivatives, and oxygenated sesquiterpenoids were accumulated in roots and rhizomes principally [46]. As expected, valerenic acidrelated compounds were shown only in root of $V$. faur$i e i$. Besides, the main compounds of root of this plant were bornyl acetate, cedrol, $\alpha$-acrorenol. These findings are quite similar to the result of Chen $\mathrm{H}$ et al.[47]. They showed that bornyl acetate were the major constituent of the essential oil from the root and rhizomes of $V$. alternifolia.

\section{Analysis of carotenoid transcript levels and carotenoid content}

We conducted real-time PCR to investigate carotenogenic transcript levels between shoot and root of $V$. fauriei and analyzed the carotenoid content by HPLC. Results revealed that the transcripts levels of carotenoid biosynthetic genes were highly expressed as maximum

Table 3 Changes in gene expression profile between shoot and root libraries

\begin{tabular}{llll}
\hline Samples & \multicolumn{2}{l}{2 fold changes } & \\
\cline { 2 - 4 } & Up & Down & Total \\
\hline Root VS Shoot & 39,145 & 6750 & 45,895 \\
\hline
\end{tabular}


Table 4 Summary for secondary metabolite genes involved in each biosynthetic pathway

\begin{tabular}{lll}
\hline Secondary metabolites & $\begin{array}{l}\text { No. unique } \\
\text { transcripts }\end{array}$ & 2 Fold \\
\hline Brassinosteroid biosynthesis & 13 & 10 \\
Flavonoid biosynthesis & 11 & 7 \\
Flavone and flavonol biosynthesis & 9 & 6 \\
Diterpenoid biosynthesis & 25 & 19 \\
Caffeine metabolism & 126 & 59 \\
Isoquinoline alkaloid biosynthesis & 158 & 89 \\
Monoterpenoid biosynthesis & 3 & 3 \\
Carotenoid biosynthesis & 46 & 33 \\
Terpenoid backbone biosynthesis & 852 & 513 \\
Anthocyanin biosynthesis & 2 & 2 \\
Sesquiterpenoid and triterpenoid & 16 & 13 \\
biosynthesis & 140 & 86 \\
Steroid biosynthesis & 310 & 194 \\
Phenylpropanoid biosynthesis & 1711 & 1044 \\
\hline Total & &
\end{tabular}

as 13.8 -fold at $L C Y E$ to a minimum of 1.31 -fold at PDS showing more in the shoot than in the root of $V$. fauriei (Fig. 7). However, expression levels of NCED and CCD, those are involved in synthesis of aprocarotenoids such as abscisic acid showed a higher level of about 1.11-, and 2.66 -fold in root than in shoot respectively. Five different carotenoids i.e., violaxanthin, zeaxanthin, $\alpha$-carotene, $\beta$ carotene, and 9-cis- $\beta$-carotene were detectedin $V$. fauriei (Table 6). Higher levels of all carotenoid content were detected in the shoot, whereas only a few quantities of $\beta$-carotene and 9 -cis- $\beta$-carotene were detected in the root of $V$. fauriei.

Carotenoids were produced in the photosynthetic organ (shoot) of $V$. fauriei in abundance. In contrast, the production of carotenoid in the underground organ (root) is rarely occurred. The results of the present study correspond well with those found in the earlier experimental studies in Chinese cabbage [48] and bitter melon [49].

\section{Analysis of phenylpropanoid transcript levels and phenolic compound content}

The genes related to phenylpropanoid biosynthetic pathway were examined both in shoot and root of $V$. fauriei (Fig. 8). Six types of phenolic compound such as chlorogenic acid, caffeic acid, ferulic acid, rutin, trans-cinnamic acid, and quercetin were found in $V$. fauriei through HPLC analysis (Table 7). Expression levels of $P A L, C 3 H$, $H Q T, F 3 H, F 3^{\prime} H, F N S$, and FNS2 were much higher in shoot than in root of $V$. fauriei, whereas a few other genes were expressed higher in root. Every phenolic compound except for chlorogenic acid and quercetin was accumulated highly in the root compared to that of in the shoot. Rutin is synthesized from quercetin by attaching one glucose and one rhamnose, catalyzed by GT and $R T$. In root of $V$. fauriei, where the level of expression of GT and $R T$ genes were higher, also the amount of rutin was higher in the root than that in the shoot. In contrast, quercetin content was more in the shoot. It may be caused due to differential gene activities of GT and $R T$ as well. Key enzymes for chlorogenic acid synthesis; $C 3 H$ and $H Q T$ were expressed at the higher level in shoot than in root and lead to a large quantity of chlorogenic acid production.

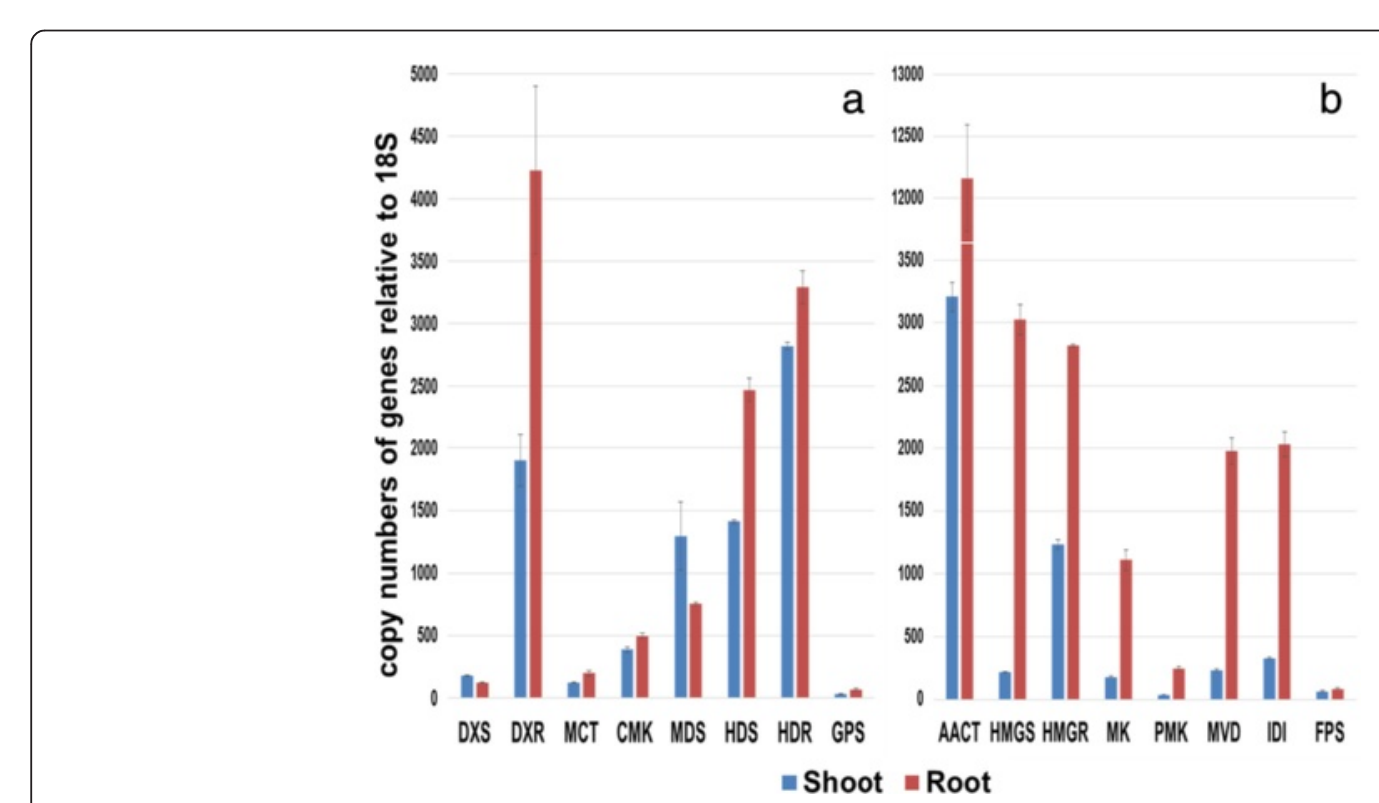

Fig. 6 Transcript levels of genes related to terpenoid biosynthetic pathway in shoot and root of $V$. fauriei. Expression levels from three individual replicates were analyzed relative to that of 18 S. Error bars showed SD values. a MEP biosynthetic genes, b MVA biosynthetic genes 
Table 5 Valerenic acid-related compounds content $(\mu \mathrm{g} / \mathrm{g}$ dry weight) in root and shoot of $V$. fauriei. Each value is from three determinations \pm SD. n.d, not detected

\begin{tabular}{llll}
\hline & Valerenic acid & Acetoxy-valerenic acid & Hydroxyvalerenic acid \\
\hline Root & $219.03 \pm 6.70$ & $32.22 \pm 0.05$ & n.d \\
Shoot & n.d & n.d & n.d \\
\hline
\end{tabular}

In some studies, phenolic compounds including luteolin, apigenin, quercetin, kaempferol, and ferulic acid have been identified from both above ground biomass and root of Valeriana family [46]. Also, Andres Navarrete et al. have demonstrated that chlorogenic acid quantified in a range of 0.2 to $2 \%$ from $V$. jatamansi, $V$. procera, $V$. edulis, $V$. sitchensis, and $V$. officinalis [50]. The wellknown phenolic compounds i.e., trans-caffeic acid and rutin were confirmed in $V$. jatamansi [51]. According to the result of Indra D. Bhatt et al., caffeic acid was highly detected in the aerial part of planted source, whereas chlorogenic acid was found in a higher amount in the root part that in aerial part of $V$. jatamansi [52]. These findings are in contrast to our results. Here in this study, it was demonstrated that caffeic acid shows quite similarly in both root and shoot of $V$. fauriei. Besides, chlorogenic acid was more in shoot of $V$. fauriei where $\mathrm{C} 3 \mathrm{H}$ and HQT genes expressed highly. The big differences with regard to chemical constituents indicated that these species are based on morphological [50].

\section{Metabolic profiles between shoot and root of $V$. fauriei using GC-TOFMS analysis}

The primary core metabolites such as organic acids, amino acids, and sugars determined using GC-TOFMS revealed clear metabolite differentiation between various biological samples. ChromaTOF software was used to support peak findings prior to quantitative analysis and for automated deconvolution of reference mass spectra. The NIST and the in-house libraries for standard chemicals were utilized for the identification of the compounds, which 42 metabolites were detected in the samples.

Principle component analysis (PCA) widely used to differentiate and correlate the components. Forty two quantified metabolites were normalized to the IS signal intensity were subjected to PCA to outline the differences between the metabolite profiles of the shoot and root samples. As shown in Fig. 9, the first and second principal components of the PCA score plot represented 89.5 and $8.7 \%$ of the total variance of the samples, respectively. The PCA results clearly showed the absence of marked variances between samples of same tissue. The corresponding loading was negative for serine, glyceric acid, threonic acid, fructose, galactose, mannitol, trehalose, and raffinose, indicating that the 8 metabolites were higher in shoot than in root. Interestingly, glucose, phenylalanine, and shikimic acid associated with terpenoid, carotenoid, and phenylpropanoid biosynthetic pathways showed higher levels in root than in shoot.

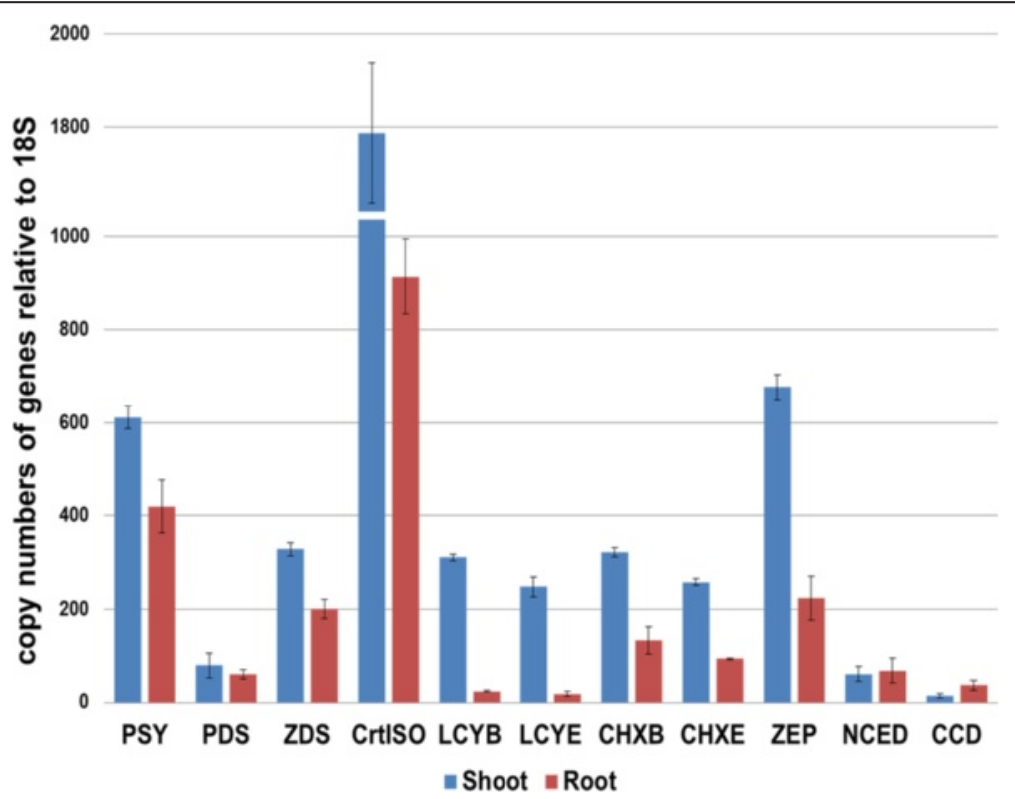

Fig. 7 Transcrip levels of genes related to carotenoid biosynthetic pathway in shoot and root of $V$. fauriei. Expression levels from three individual replicates were analyzed relative to that of 185 . Error bars showed SD values 
Table 6 Carotenoid content ( $\mu \mathrm{g} / \mathrm{g}$ dry weight) in root and shoot of $V$. fauriei. Each value is from three determinations \pm SD. n.d, not detected

\begin{tabular}{lllllrr}
\hline & Violaxanthin & Zeaxanthin & a-carotene & $\beta$-carotene & 9-cis- $\beta$ carotene & Total \\
\hline Root & n.d & n.d & n.d & $0.42 \pm 0.05$ & $0.05 \pm 0.01$ & $0.47 \pm 0.05$ \\
Shoot & $0.16 \pm 0.05$ & $10.38 \pm 2.08$ & $0.19 \pm 0.04$ & $2.99 \pm 0.77$ & $0.32 \pm 0.11$ & $14.04 \pm 3.05$ \\
\hline
\end{tabular}

Combined transcriptome and targeted metabolic profiling data possibly provides correlations between genes and metabolites in given biological systems on a wholegenome or metabolome scale [53]. Also, NGS with metabolomics tools can provide insight into the nature of transcript-metabolite networks because of the increased ease and efficiency [54].

In further study, we expect that tissue-specific transcript profiling can provide insights into biological, functional differences between independent transcripts of both shoot and root of $V$. fauriei. In addition, there is an opportunity to produce medicinal substances for industrial purposes in both quality and quantity through genetic engineering.

\section{Conclusions}

In present study, we obtained a total of 97,959 unigenes using Illumina HiSeq system from $V$. fauriei. Among them, there were 47,760 annotated genes with Uniprot BLAST hits and mapped to GO, COG, and KEGG pathway. Individually, 70,013 transcripts and 88,827 transcripts were expressed in root and shoot, respectively of $V$. fauriei. Transcripts were highly involved in terpenoid backbone biosynthesis and phenylpropanoid biosynthesis compared to other biosynthesis by grouping into KEGG secondary metabolite biosynthetic pathway. Therefore, we found that de novo transciptome sequencing with DGE analysis is a modern novel technique for the identification of specific genes for the candidate enzymes involved in the biosynthesis of secondary metabolites in $V$. fauriei. We also investigated the expression of genes suggested an association with secondary metabolism in root and shoot of $V$. fauriei. Most of genes related to terpenoid biosynthesis are highly expressed in root than in shoot of $V$. fauriei. Also, we confirmed the presence of about 130 volatile compounds those are isolated from $V$. fauriei using GC/MS and also it is mentionable that valerenic acid-related compounds are shown only in the root of this plant. However, all carotenoid biosynthetic genes except NCED and CCD were expressed in a higher rate in the shoot than that of in the root of this plant. In addition, carotenoids were commonly accumulated in shoot. A couple of phenylpropanoid biosynthetic genes are expressed higher in the shoot and others are expressed in a higher rate in the root of $V$. fauriei showing in different amounts.

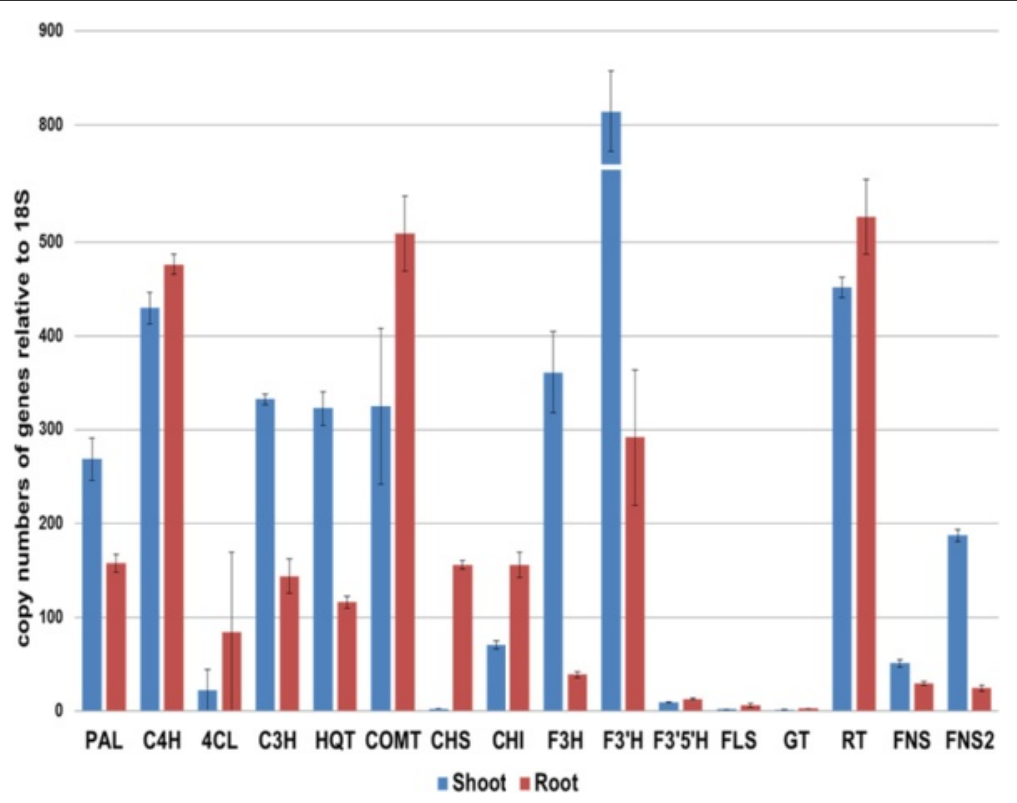

Fig. 8 Transcript levels of genes related to phenylpropanoid biosynthetic pathway in shoot of root of $V$. fauriei. Expression levels from three individual replicates were analyzed relative to that of 185 . Error bars showed SD values 
Table 7 Phenolic compounds ( $\mu \mathrm{g} / \mathrm{mg}$ dry weight) in root and shoot of $V$. fauriei. Each value is from three determinations \pm SD. n.d, not detected

\begin{tabular}{lclllll}
\hline & Chlorogenic acid & Caffeic acid & Ferulic acid & Rutin & Trans-cinnamic acid & Quercetin \\
\hline Root & $3.819 \pm 0.002$ & $0.193 \pm 0.001$ & $0.236 \pm 0.004$ & $0.836 \pm 0.000$ & $0.004 \pm 0.001$ & $0.002 \pm 0.001$ \\
Shoot & $14.726 \pm 0.128$ & $0.185 \pm 0.001$ & $0.015 \pm 0.001$ & $0.288 \pm 0.006$ & $0.002 \pm 0.000$ & $0.016 \pm 0.000$ \\
\hline
\end{tabular}

According to transcriptome databases, the comparison of gene expression and metabolite accumulation were achieved in this study. The transcriptome analysis for $V$. fauriei gives an opportunity to characterize genes leading to the synthesis of secondary metabolites, compounds of interest.

\section{Methods}

\section{Plant materials and RNA isolation}

$V$. fauriei seeds were collected from Rural Development Administration (RDA, Korea) and $V$. fauriei plants were established in a greenhouse at the experimental farm of Chungnam National University (Daejeon, Korea). Any temperature condition or additional illumination has not been regulated to the cultures. The plantlets were exposed to outdoor conditions in the greenhouse for 2 months between 19.05.2014 and 20.07.2014. Average temperature in this season was $21.8{ }^{\circ} \mathrm{C}$. Plant materials were excised from 2-month-old young seedling plants and dissected into shoot (leave and stems) and root (roots and rhizomes). The separated plant parts were washed thoroughly with sterile water and frozen in liquid nitrogen immediately and stored at $-80{ }^{\circ} \mathrm{C}$. Shoot and root of $V$. fauriei were ground with liquid nitrogen. Total RNA was extracted from each part of $V$. fauriei separately using the Total RNA Mini Kit (Geneaid, Taiwan) by following the catalogues instruction and the concentrations were determined by agarose gel electrophoresis and NanoVue Plus Spectrophotometer (GE Healthcare Bio-Science Crop, USA) respectively. All samples were harvested and RNA isolation was performed in triplicate.

\section{Sequence analysis}

Illumina sequencing data was used for the identification of genes involved in terpenoid backbone, carotenoid,
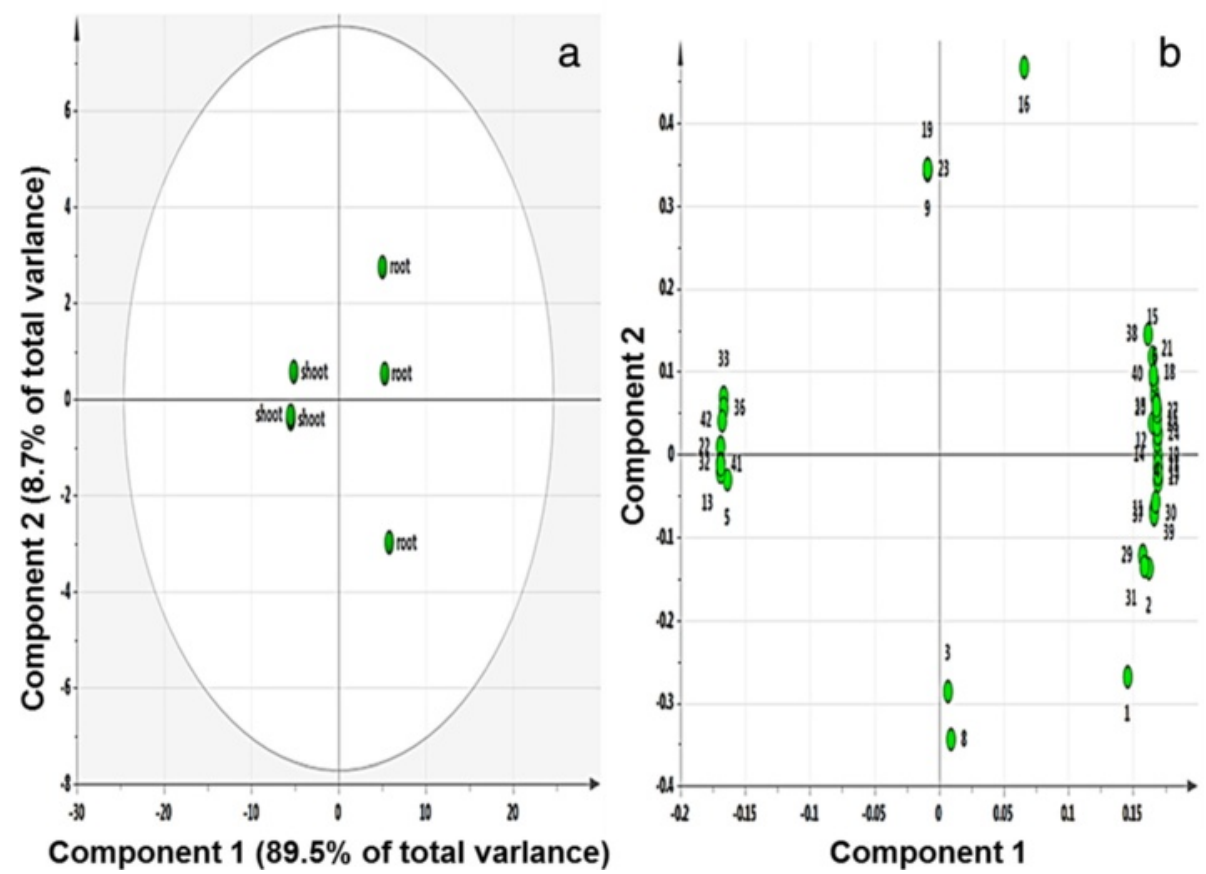

Fig. 9 PCA score plots (a) and loading plots (b) derived from polar metabolites of shoot and root of $V$. fauriei. PC1 and PC2 accounted for >98.2\% of the total variance. The ellipse represents the Hotelling T2 with $95 \%$ confidence in the score plot. The loading plots represent the original variables in the space of the PCs. They reveal the magnitude and direction of correlation of the original variables with the first two PCs. 1, lactic acid; 2, valine; 3 , alanine; 4, glycolic acid; 5, serine; 6, ethanolamine; 7, glycerol; 8, isoleucine; 9, proline; 10, nicotinic acid; 11, glycine; 12, succinic acid; 13 , glyceric acid; 14, fumaric acid; 15, threonine; 16, $\beta$-alanine; 17, malic acid; 18, aspartic acid; 19, methionine; 20, pyroglutamic acid; 21, 4-aminobutyric acid; 22 , threonic acid; 23, arginine; 24, glutamic acid; 25, phenylalanine; 26, xylose; 27, asparagine; 28, glutamine; 29, shikimic acid; 30, citric acid; 31, quinic acid; 32 , fructose; 33, galactose; 34, glucose; 35, mannose; 36, mannitol; 37, inositol; 38, tryptophan; 39, sucrose; 40, maltose; 41, trehalose; 42, raffinose 
and phenylpropanoid metabolic biosynthetic pathway. The individual candidate gene name was searched using the functional annotation file. The selected amino acid sequences of the genes were analyzed for homology using BLAST at the NCBI Genbank database (http:// www.ncbi.nlm.nih.gov/BLAST).

\section{Next generation sequencing of transcriptome}

To obtain high-throughput transcriptome data of $V$. fauriei, we implemented Illumina-based NGS sequencing. Total RNAs were quantified using Nanodrop spectrophotometer (Thermo Scientific) and quality-assessed by RNA 6000 Nano assay kit (Agilent) and Bioanalyser 2100 (Agilent). NGS sequencing libraries were generated from one microgram of total RNA using Truseq RNA Sample Prep Kit (Illumina) according to the manufacturer's protocol. In brief, the poly-A containing RNA molecules were purified using poly- $\mathrm{T}$ oligo attached magnetic beads. After purification, the total poly A+ RNA was fragmented into small pieces using divalent cations under elevated temperature. The cleaved mRNA fragments were reverse transcribed into first strand cDNA using random primers. QiaQuick PCR extraction kit was used for the purification of the shorts fragments and further resolved with EB buffer for end reparation and addition of poly (A). After that, the short fragments with poly (A) tail were interlinked with sequencing adapters. Each library was separated by adjoining distinct MID tag. The resulting cDNA libraries were then paired-end sequenced (2x101bp) with Illumina HiSeq ${ }^{\mathrm{mix}}$ 2500 system.

\section{De novo assembly}

Complete paired end sequences were obtained as individual fastq files (forward and reverse) from the images by CASAVA (version 1.8.2) base calling software with ASCII Q-score offset 33. Adaptor sequences and low quality bases with PHERD scores $(\mathrm{Q}) \leq 20$, were removed. Repeat sequences in raw reads were masked by using Repeat Makser against Arabiopdopsis Rep base database. Simple sequence repeats and low complexity sequences were also masked by using SSRIT and DUST software respectively [55]. Finally, masked sequences were subjected to de novo assembly by using CLC Assembly Cell v.4.0 (CLCBio, Inc. Denmark) with customized parameters. To optimize transcriptome assembly, a set of assembly was done with word size of 21 to 63 with increment of 2 (data not shown). From the different assemblies, the best one was selected based on the sequence mapping coverage which was assessed by reference mapping of clean reads to an individual assembly with CLC mapper with length fraction $80 \%$ and similarity $90 \%$. Based on the reference mapping results, the assembly with word size 63 was chosen as the best assembly. To remove the isoforms and obtain the nonredundant sequence set from the selected assembly contigs, CAP3 [56]was performed with default parameters. Finally, results from CAP3 (singletons and contigs) were merged together to generate reference transcriptome assembly and renamed with unique sequence identifiers.

\section{Functional annotations}

Non-redundant transcripts (per se reference transcriptome) were subjected to functional annotations by sequence homology search against biological databases such as GO, KEGG, and COG. Sequences were first mapped to UniProt database using BLASTX with evalue cut-off of 1e-5. Biological descriptions, GO terms, KEGG, and COG identifiers were transferred from the best-matched UniProt entry among the mapped sequence for each sequence. Then, the gene ontology functional classifications such as biological process (BP), molecular function (MF) and cellular components (CC), were grouped according to the GO hierarchy level 2 and the distributions were plotted using WEGO [57]. Similarity, e-value, and species distributions were calculated from BLAST results. Transcripts were also grouped according to KEGG map IDs. Finally, sequence descriptions and references were collected from UniProt database using biopython module.

\section{Digital gene expression (DGE) profiling and selection of transcripts involved in secondary metabolic pathway}

To characterize the quantitative expression profile of individual sequence, the clean sequence reads from two libraries (root and shoot) were mapped individually to the reference transcriptome using CLC mapper with $90 \%$ similarity and $80 \%$ length fraction respectively. Based on the read count to each transcript, the reads per kilo base per million (RPKM) value was calculated. RPKM $=\left(10^{9} * \mathrm{C}\right) / \mathrm{N} * \mathrm{~L}$. C is number of mapped reads per sequence, $\mathrm{N}$ is total number of mapped reads and $\mathrm{L}$ is length of the sequence [58]. The statistical significance difference between the expression levels of each transcript within each pair of conditions were assessed by Audic and Claveriae' method and false discovery (FDR) rate control $[40,59]$. RPKM values were taken to Gene Spring 12.5 GX to calculate the fold changes (FC) through 2 libraries with default parameter. Fold changes were calculated for category such as root vs Shoot. Finally, sequence were filtered with RPKM $\geq 0.3$, FDR $>0.001$ and $F C \geq 2.0$ [42]. Annotations obtained from the UniProt database such as gene descriptions, GO terms and sequence descriptions were manually examined from the known keywords (referred by published articles and KEGG pathways) for the candidate gene selections of secondary metabolism related. 
cDNA synthesis and quantitative real-time PCR

cDNA was synthesized from $1 \mu \mathrm{g}$ of total RNA using the ReverTra Ace- $\alpha$ Kit (Toyobo, Osaka, Japan). For all target genes and the $18 S$ gene, an internal reference, primers were designed with GenScript Real-time PCR (TaqMan) Primer Design (www.genscipt.com) to conduct quantitative real-time PCR (Additional file 8). Quantitative real-time PCR was performed in a BIORAD CFX96 Real-time PCR system (Bio-Rad Laboratories, Hercules, CA) with the 2X Real-Time PCR smart mix (Solgent Co., Ltd. Daejeon, Korea) under the following conditions: pre-denaturation at $95{ }^{\circ} \mathrm{C}$ for $15 \mathrm{~min}$, denaturation for $20 \mathrm{~s}$ at $95{ }^{\circ} \mathrm{C}$, and reaction cycle was repeated for 39 cycles at annealing for $40 \mathrm{~s}, 20 \mathrm{~s}$ at $72{ }^{\circ} \mathrm{C}$ and final extension at $72{ }^{\circ} \mathrm{C}$ for $10 \mathrm{~min}$. The differences between treatment means were evaluated from tree independent replicates for each sample. Then, average mean value and standard deviation value from three replicates of respective samples were analyzed.

\section{Analysis of GC and GC-mass spectrometry}

Ten gram of the fresh shoot and root of $V$. fauriei were weighed and transferred into $25 \mathrm{ml}$ headspace vials. A fused-silica fiber covered with a $75 \mu \mathrm{m}$ layer of carboxen/polydimethylsiloxane (CAR/PDMS) was used for absorption of the volatile compounds in the fresh shoot and root. The vials containing the samples and the solvents were kept at $25{ }^{\circ} \mathrm{C}$ for $20 \mathrm{~min}$ and was then removed from the vial and injected into the $\mathrm{GC}$ where analysis was performed at $250{ }^{\circ} \mathrm{C}$ for $3 \mathrm{~min}$.

GC analysis was performed using an Agilent $6890 \mathrm{~N}$ GC mainframe equipped with an HP-5 (30 $\mathrm{m} \times$ $0.32 \mathrm{mmID}$, film thickness $0.25 \mu \mathrm{m}$ ) fused-silica capillary column (Agilent, USA) and a flame ionization detector. The injector and detector temperatures for each analysis were 250 and $280{ }^{\circ} \mathrm{C}$, respectively. The carrier gas was nitrogen at a flow rate of $1.0 \mathrm{~mL} \cdot \mathrm{min}^{-1}$. The column temperature was maintained at $50{ }^{\circ} \mathrm{C}$ for $5 \mathrm{~min}$ and afterward programmed as follow : increase from 50 to $260{ }^{\circ} \mathrm{C}$ at a rate of $3{ }^{\circ} \mathrm{C} \cdot \mathrm{min}^{-1}$, increase from 260 to $280{ }^{\circ} \mathrm{C}$ at a rate of $10^{\circ} \mathrm{C} \cdot \mathrm{min}^{-1}$ and hold at $280{ }^{\circ} \mathrm{C}$ for $5 \mathrm{~min}$.

GC-MS analysis was performed on a GC/MSD Polaris Q (thermoFinnigan, USA) with an HP-5 (30 $\mathrm{m} \times$ $0.32 \mathrm{~mm}$ ID, film thickness $0.25 \mu \mathrm{m}$ ) fused-silica capillary column (Agilent, USA). Helium was used as the carrier gas at a flow rate of $1.0 \mathrm{~mL} \cdot \mathrm{min}^{-1}$. For GC-MS detection, an electron ionization system with system energy $70 \mathrm{eV}$, trap current $250 \mu \mathrm{A}$, and ion source temperature $200{ }^{\circ} \mathrm{C}$ was used. The oven temperature program was the same as that described for GC, and injections were used in the split less mode. To identify of samples, components compared of mass spectra with the NIST and WILLY library data of the GC-MS system and with data from the literature. Total ion current chromatograms were recorded in a mass rage of 40400 amu.

\section{High performance liquid chromatography analysis}

Collected samples were dried in the freeze-dryer at $-80{ }^{\circ} \mathrm{C}$ for 3 days. Dried samples were ground into a fine powder using a mortar and pestle.

\section{Quantification of valerenic acid and its derivatives}

One gram of powdered samples was extracted with $10 \mathrm{~mL}$ of $90 \%(\mathrm{v} / \mathrm{v})$ methanol at room temperature for $30 \mathrm{~min}$ and the extracts were centrifuged at 12,000 rpm for $10 \mathrm{~min}$. This step was repeated for three times. Thereafter, the final extract were evaporated using LABOROTA 4000 (Heidolph, Germany) and filtered with a $0.45-\mu \mathrm{m}$ Acrodisc syringe filter (Pall Corp.; Port Washington, NY), for HPLC analysis. HPLC analysis was performed with a C18 column ( $\mu$ Bondapak $^{\text {TM }}$ C18 $10 \mu \mathrm{m} 125 \AA 3.9 \times 300 \mathrm{~nm}$ column). The mobile phase was a gradient prepared from mixtures of acetonitrile and $0.25 \%$ phosphoric acid and the column temperature was maintained at $30{ }^{\circ} \mathrm{C}$. The flow rate was maintained at $0.7 \mathrm{~mL} / \mathrm{min}$. Injection volume of $20 \mu \mathrm{L}$ and $221 \mathrm{~nm}$ wavelengths were used for detection. The compounds of standard were determined by using a standard curve.

\section{Carotenoid}

For carotenoids quantification, $300 \mathrm{mg}$ of $V$. fauriei samples were mixed with $3 \mathrm{ml}$ of ethanol containing $0.1 \%$ ascorbic acid $(\mathrm{w} / \mathrm{v})$. This mixture was mixed throughly for a while, then incubated in a water bate at $85{ }^{\circ} \mathrm{C}$ for $5 \mathrm{~min}$. In subsequent step, separately $120 \mu \mathrm{l}$ of potassium hydroxide $(80 \% \mathrm{w} / \mathrm{v})$ was added to saponify any potential interfering oils. After vortex, incubated at $85^{\circ}$ $\mathrm{C}$ for $10 \mathrm{~min}$ again and immediately keep it ice for $5 \mathrm{~min}$. Separately, $1.5 \mathrm{ml}$ of cold deionized water was mixed with $0.05 \mathrm{ml}$ of b-Apo-80-carotenal $(1.25 \mu \mathrm{g})$ was added to mixture as an internal standard. $1.5 \mathrm{ml}$ of hexane was used for the extraction of extraction of complete carotenoids. The isolated carotenoids layers were separated by centrifugation at $1200 \mathrm{rpm}$ for $10 \mathrm{~min}$. The resulting extracts were freeze-dried by passing nitrogen gas and resuspended in 50:50 (v/v) dichloromethane/ methanol. The carotenoids were separated on an Agilent 1260 HPLC system. The separating solvent consists of mixture of solvent A (methanol/water (92\% v/v) including $10 \mathrm{mM}$ ammonium acetate) and solvent $\mathrm{B}$ consisted of $100 \%$ methyl tert-butyl ether (MTBE). The separating solvents were flow at $1.0 \mathrm{ml} / \mathrm{min}$ and the injection sling was $20 \mu \mathrm{l}$. Samples were eluted with the following gradient: $0 \mathrm{~min}, 90 \% \mathrm{~A} / 10 \% \mathrm{~B} ; 20 \mathrm{~min}, 83 \% \mathrm{~A} / 17 \% \mathrm{~B}$; $29 \min , 75 \% \mathrm{~A} / 25 \% \mathrm{~B}, 35 \mathrm{~min}, 30 \% \mathrm{~A} / 70 \% \mathrm{~B} ; 40 \mathrm{~min}$, $30 \% \mathrm{~A} / 70 \% \mathrm{~B} ; 42 \mathrm{~min}, 25 \% \mathrm{~A} / 75 \% \mathrm{~B} ; 45 \mathrm{~min}, 90 \%$ $\mathrm{A} / 10 \% \mathrm{~B} ; 55 \mathrm{~min}, 90 \% \mathrm{~A} / 10 \% \mathrm{~B}$. With the help of 
previous guidelines, based on the retention time and UV-visible spectrum data, carotenoids were identified.

\section{Phenolic compound}

Phenolic compounds extracted by mixing $100 \mathrm{mg}$ samples with $80 \%$ methanol at room temperature for $1 \mathrm{~h}$ in a $10 \mathrm{ml}$ sterile test tube. After proper mixing, the crude mixture was centrifuged and the supernatant was filtered through $0.45 \mu \mathrm{m}$ filter before HPLC analysis. Individual phenolic compounds were eluted, separated and quantified in a Futecs model NS-4000 HPLC apparatus (Daejeon, Korea). The HPLC analysis was performed in $\mathrm{C} 18$ column (maintained at $30{ }^{\circ} \mathrm{C}$ ) and the phenolic compounds were detected at $280 \mathrm{~nm}$. Gradient mobile phase system [water: acetic acid $(98: 2 \mathrm{v} / \mathrm{v})$ ] was used for the elution of the phenolic compounds. The gradient solvents were flown at $1.0 \mathrm{ml} / \mathrm{min}$ and $20 \mu \mathrm{l}$ of the sample was used for injection. The contents of individual phenol compounds were calculated using a standard calibration curve. All samples were run in triplicate.

\section{GC-TOFMS analysis of polar metabolites}

The extraction of polar metabolite was performed as described by Kim et al. (2013) [60]. The sample preparation methods, chemicals and reagents, esterification procedures, GC-TOFMS instrument operating conditions, analytical methods for the separation of the samples and the scanning and the detection of the compounds rang were as implemented as described in our previous research paper [58].

\section{Statistical analysis}

In $V$. fauriei samples, 42 metabolites were identified by GC-TOFMS. The quantitative calculations of all analytes were based on the peak area ratios relative to that of the IS. The relative quantification data acquired from GCTOFMS were subjected to PCA (SIMCA-P version 13.0; Umetrics, Umeå, Sweden) to evaluate the relationships in terms of similarity or dissimilarity among groups of multivariate data. The PCA output consisted of score plots to visualize the contrast between different samples and loading plots to explain the cluster separation. The data file was scaled with unit variance scaling before all the variables were subjected to the PCA.

\section{Ethics approval and consent to participate \\ Not applicable.}

\section{Consent for publication}

Not applicable.

\section{Availability of data and material}

The datasets supporting the conclusions of this article are included within the article and its additional files.

\section{Additional files}

\begin{abstract}
Additional file 1: Terpenoid biosynthesis pathway in plants. AACT, acetoacetyl-CoA thiolase; CMK, 4-(cytidine 5'-diphospho)-2-C-methyl-Derythritol kinase; DMAPP, dimethylallyl diphosphate; DXR, 1-deoxy-D-xylulose 5-phosphate reductoisomerase; DXS, 1-deoxy-D-xylulose 5-phosphate synthase; FPS, farnesyl diphosphate synthase; GPS, geranyl diphosphate synthase; HDR, 4-hydroxy-3-methylbut-2-enyl diphosphate reductase; HDS, 4-hydroxy-3-methylbut-2-enyl diphosphate synthase; HMGR,

hydroxymethylglutaryl-CoA reductase; HMGS, hydroxymethylglutaryl-CoA synthase; IDI, isopentenyl diphosphate isomerase; IPP, isopentenyl diphosphate; MCT, 2-C-methyl-D-erythritol 4-phosphate cytidylyltransferase; MDS, 2-C-methyl-D-erythritol 2,4-cyclodiphosphate synthase; MVD, mevalonate diphosphate decarboxylase; MK, mevalonate kinase; PMK, 5-
\end{abstract}

phosphomevalonate kinase. (PDF $160 \mathrm{~kb}$ )

Additional file 2: Carotenoid biosynthesis pathway in plants. $C C D$, carotenoid cleavage dioxygenases; $C H X B, \beta$-ring hydroxylase; $C H X E$, $\varepsilon$-ring hydroxylase, CrtISO; carotenoid isomerase; $L C Y B$, lycopene $\beta$-cyclase; $L C Y E$, lycopene $\varepsilon$-cyclase; NCED, nine-cis-epoxycarotenoiddioxygenanses; PDS, phytoene desaturase; PSY, phytoene synthase; ZDS, Z-carotene desaturase; ZEP, zeaxanthin epoxidase. (PDF $154 \mathrm{~kb}$ )

Additional file 3: Phenylpropanoid biosynthesis pathway in plants. $4 \mathrm{CL}$, 4-coumaroyl CoA ligase; $\mathrm{C} 3 \mathrm{H}$, p-coumarate-3-hydroxylase; $\mathrm{C} 4 \mathrm{H}$, cinnamate 4-hydroxylase; $\mathrm{CH}$, chlacone isomerase; CHS, chalcone synthase; COMT, caffeate O-methyltransferase; $F 3 H$, flavone-3-hydroxylase; $F 3^{\prime} H$, flavonoid3'-hydroxylase; F3'5'H, flavonoid $3^{\prime} 5^{\prime}$-hydroxylase, FLS, flavonol synthase; FNS I, II, flavone synthase I, II; GT, flavonoid 3-O-glucosyltransferase; HQT, hydroxycinnamoyl-CoA quinate hydroxyl cinnamoyl transferase; PAL, phenylalanine ammonia-lyase; RT, flavonol 3-O-glucoside Lrhamnosyltransferase. (PDF 147 kb)

Additional file 4: Comparison of terpenoid biosynthetic genes of $\mathrm{V}$. fauriei with the most orthologous genes. (XLS 34 kb)

Additional file 5: Comparison of carotenoid and phenylpropanoid biosynthetic genes of $V$. fauriei with the most orthologous genes. (XLS $40 \mathrm{~kb}$ )

Additional file 6: Amount of terpenes in $V$. fauriei by solid-phase micro-extraction (\%) (XLS $31 \mathrm{~kb}$ )

Additional file 7: Amount of other volatile compounds in $V$. fauriei by solid-phase micro-extraction (\%). (XLS 34 kb)

Additional file 8: Primers used to amplify $V$. fauriei genes. (XLS $40 \mathrm{~kb}$ )

\section{Competing interests}

The authors declare that they have no competing interest.

\section{Authors' contributions}

Conceived and designed the experiments: SUP and NAA. Performed the experiments and analyzed the data: YJP, XL, SJN, JKK, SSL, NIP, SK, YBK, YOK, and SWL. Wrote the manuscript: YJP, SJN, JKK, MVA, and SUP. All authors read and approved the final manuscript.

\section{Acknowledgement}

This work was carried out with the support of "Cooperative Research Program for Agriculture Science \& Technology Development (Project No. PJ011582022015)" Rural Development Administration, Republic of Korea and was supported by the grant entitled "The Genetic and Genomic Evaluation of Indigenous Biological Resources" funded by the National Institute of Blological Resources (NIBR201503101). The authors would like to extend their sincere appreciation to the Deanship of Scientific Research at King Saud University for its funding of this research through the Research Group project NO (RG-1435-071).

\section{Author details}

'Department of Crop Science, Chungnam National University, 99 Daehak-ro, Yuseong-gu, Daejeon 305-764, Korea. '2Code Division, Insilicogen Inc., Suwon, Gyeonggi-do 441-813, Korea. ${ }^{3}$ Division of Life Sciences and Bio-Resource and Environmental Center, Incheon National University, Yeonsu-gu, Incheon 406-772, Korea. ${ }^{4}$ Department of Food and Nutrition and Institute of Natural Medicine, Hallym University, Chuncheon 200-702, Korea. ${ }^{5}$ Deptartment of 
Plant Science, Gangneung-Wonju National University, 7 Jukheon-gil, Gangneung-si, Gangwon-do 210-702, Korea. ${ }^{6}$ Biological and Genetic Resources Assessment Division, National Institute of Biological Resources, Incheon 404-170, Korea. ${ }^{7}$ Department of Herbal Crop Research, National Institute of Horticultural and Herbal Science (NIHHS), Rural Development Administration (RDA), Bisanro 92, Eumseong, Chungbuk 369-873, Republic of Korea. ${ }^{8}$ Department of Botany and Microbiology, Addiriyah Chair for Environmental Studies, College of Science, King Saud University, P. O. Box 2455, Riyadh 11451, Saudi Arabia.

\section{Received: 11 August 2015 Accepted: 13 April 2016} Published online: 23 April 2016

\section{References}

1. Osima Y, Matsuoka S, Ohizumi Y. Antidepressant principles of Valeriana fauriei roots. Chem Pharm Bull. 1995;43(1):169-70.

2. Sharma M, Jain UK, Patel A, Gupta N. A Comprehensive Pharmacognostic Report on Valerian. Int J Pharma Sci Res. 2010;1(7):6-40.

3. Raal A, Orav A, Arak E, Kailas T, Müürisepp M. Variation in the composition of the essential oil of Valeriana officinalis L. roots from Estonia. Proc Estonian Acad Sci Chem. 2007;56(2):67-74.

4. Liu X-G, Zhang W-C, Gao P-Y, Wang G-S, Li L-Z, Song S-J, Zhang X, Yao X-S, Liu K, Zhang Z-X. Two New Sesquiterpenes from the Roots of Valeriana fauriei Briq. Helvetica Chimica Acta. 2013;96:651-5.

5. Houghton PJ. The Scientific Basis for the Reputed Activity of Valerian. J Pharm Pharmacol. 1999;51:505-12.

6. Zhenxue Z, Xinsheng Y. Progress on chemical studies of Valeriana. Chin J Med Chem. 2000;10:226-30.

7. Mathela CS, Chanotiya CS, Sammal SS, Pant AK, Pandey S. Compositional Diversity of Terpenoids in the Himalayan Valeriana Genera. Chem Biodivers. 2005;2(9):1174-82.

8. Bos R, Woerdenbag HJ, van Putten FM, Hendriks H, Scheffer JJ. Seasonal Variation of the Essential Oil, Valerenic Acid and Derivatives, and Valepotriates in < EM EMTYPE=. Planta Med. 1998;64(02):143-7.

9. Yuan C-S, Mehendale S, Xiao Y, Aung HH, Xie J-T, Ang-Lee MK. The GammaAminobutyric Acidergic Effects of Valerian and Valerenic Acid on Rat Brainstem Neuronal Activity. Anesth Analg. 2004;98(2):353-8.

10. Dudareva N, Pichersky E, Gershenzon J. Biochemistry of Plant Volatiles. Plant Physiol. 2004;135:1893-902.

11. Dudareva N, Negre F, Nagegowda DA, Orlova I. Plant Volatiles: Recent Advances and Future Perspectives. Crit Rev Plant Sci. 2006;25(5):417-40.

12. Nagegowda DA. Plant volatile terpenoid metabolism: Biosynthetic genes, transcriptional regulation and subcellular compartmentation. Fed Eur Biochem Soc. 2010;584:2965-73.

13. Hemmerlin A, Hoeffler J-F, Meyer O, Tritsch D, Kagan IA, GrosdemangeBilliard C, et al. Cross-talk between the Cytosolic Mevalonate and the Plastidial Methylerythritol Phosphate Pathways in Tobacco Bright Yellow-2 Cells. J Biol Chem. 2003;278:26666-76.

14. Howitt CA, Pogson BJ. Carotenoid accumulation and function in seeds and non-green tissues. Plant, Cell Environ. 2006;29:435-45.

15. Shumskaya M, Wurtzel ET. The carotenoid biosynthetic pathway: Thinking in all dimensions. Plant Sci. 2013;208:58-63.

16. Sandmann G. Evolution of carotene desaturation: The complication of a simple pathway. Arch Biochem Biophys. 2009;483(2):169-74.

17. Clotault J, Peltier D, Berruyer R, Thomas M, Briard M, Geoffriau E. Expression of carotenoid biosynthesis genes during carrot root development. J Exp Bot. 2008;59(13):3563-73.

18. Cazzonelli $\mathrm{Cl}$. Carotenoids in nature: insights from plants and beyond. Funct Plant Biol. 2011:38:833-47.

19. Auldridge ME, McCarty DR, Klee HJ. Plant carotenoid cleavage oxygenases and their apocarotenoid products. Curr Opin Plant Biol. 2006;9(3):315-21.

20. Vogt T. Phenylpropanoid Biosynthesis. Mol Plant. 2010;3(1):2-20.

21. Christelle M, Andréa B, Schafleitnerc $R$, Legaya $S$, Lefèvrea I, Aliagac CAA, et al. Gene expression changes related to the production of phenolic compounds in potato tubers grown under drought stress. Phytochemistry. 2009;70(9):1107-16.

22. Fraser CM, Chapple C. The Phenylpropanoid Pathway in Arabidopsis. Arabidopsis book 2011:e1052. doi:10.1199/tab.0152.

23. Martens S, Preuß A, Matern U. Multifunctional flavonoid dioxygenases: Flavonol and anthocyanin biosynthesis in Arabidopsis thaliana L. Phytochemistry. 2010;71(10):1040-9.
24. Angeloni F, Wagemaker CAM, Jetten MSM, Camp HJMOD, Janssen-Megens EM, Francoijs K-J, et al. De novo transcriptome characterization and development of genomic tools for Scabiosa columbaria L. using nextgeneration sequencing techniques. Mol Ecol Resour. 2011;11:662-74.

25. Glenn TC. Field guide to next-generation DNA sequencers. Mol Ecol Resour. 2011;11:759-69.

26. Xia J, Wang Q, Jia P, Wang B, Pao W, Zhao Z. NGS Catalog: A Database of Next Generation Sequencing Studies in Humans. Human Mutation Database in Brief. 2012;33(6):E2341-55.

27. Morozova O, Hirst M, Marra MA. Applications of New Sequencing Technologies for Transcriptome Analysis. Annu Rev Genomics Hum Genet. 2009;10(1):135-51.

28. Garg R, Jain M. RNA-Seq for transcriptome analysis in non-model plants. Methods Mol Biol. 2013;1069:43-58.

29. Strausberg RL, Levy S, Rogers $Y-H$. Emerging DNA sequencing technologies for human genomic medicine. Drug Discov Today. 2008;13:569-77.

30. Li R, Fan W, Tian G, Zhu H, He L, Cai J, Huang Q, Cai Q, Li B, Bai Y. The sequence and de novo assembly of the giant panda genome. Nature. 2009:463(7279):311-7.

31. Wang Z, Gerstein M, Snyder M. RNA-Seq: a revolutionary tool for transcriptomics. Nat Rev Genet. 2009;10(1):57-63.

32. Guo Q, Ma X, Wei S, Qiu D, Wilson IW, Wu P, Tang Q, Liu L, Dong S, Zu W. De novo transcriptome sequencing and digital gene expression analysis predict biosynthetic pathway of rhynchophylline and isorhynchophylline from Uncaria rhynchophylla, a non-model plant with potent anti-alzheimer's properties. BMC Genomics. 2014;15(1):676.

33. Imelfort $M$, Edwards D. De novo sequencing of plant genomes using second-generation technologies. Brief Bioinform. 2009;10(6):609-18.

34. Wong MM, Cannon $\mathrm{CH}$, Wickneswari R. Identification of lignin genes and regulatory sequences involved in secondary cell wall formation in Acacia auriculiformis and Acacia mangium via de novo transcriptome sequencing. BMC Genomics. 2011;12(1):342

35. Kudapa H, Bharti AK, Cannon SB, Farmer AD, Mulaosmanovic B, Kramer R, Bohra A, Weeks NT, Crow JA, Tuteja R. A comprehensive transcriptome assembly of pigeonpea (Cajanus cajan L.) using Sanger and secondgeneration sequencing platforms. Mol Plant. 2012;5(5):1020-8.

36. Barrero RA, Chapman B, Yang Y, Moolhuijzen P, Keeble-Gagnère G, Zhang N Tang Q, Bellgard MI, Qiu D. De novo assembly of Euphorbia fischeriana root transcriptome identifies prostratin pathway related genes. BMC Genomics. 2011;12(1):600.

37. Feng C, Chen M, Xu C-J, Bai L, Yin X-r, Li X, Allan AC, Ferguson IB, Chen K-s. Transcriptomic analysis of Chinese bayberry (Myrica rubra) fruit development and ripening using RNA-Seq. BMC Genomics. 2012;13(1):19.

38. Zhou Y, Gao F, Liu R, Feng J, Li H. De novo sequencing and analysis of root transcriptome using 454 pyrosequencing to discover putative genes associated with drought tolerance in Ammopiptanthus mongolicus. BMC Genomics. 2012;13(1):266.

39. Tang Q, Ma X, Mo C, Wilson IW, Song C, Zhao H, Yang Y, Fu W, Qiu D. An efficient approach to finding Siraitia grosvenorii triterpene biosynthetic genes by RNA-seq and digital gene expression analysis. BMC Genomics. 2011;12:343.

40. Audic S, Claverie J-M. The significance of digital gene expression profiles. Genome Res. 1997:7(10):986-95.

41. Subramanian A, Tamayo P, Mootha VK, Mukherjee S, Ebert BL, Gillette MA, Paulovich A, Pomeroy SL, Golub TR, Lander ES. Gene set enrichment analysis: a knowledge-based approach for interpreting genome-wide expression profiles. Proc Natl Acad Sci U S A. 2005;102(43):15545-50.

42. Wei Z, Wanxia X, Jiewen L, Shujing S, Lei L, Shujing Z. Transcriptome profiling and digital gene expression analysis of Fallopia multiflora to discover putative genes involved in the biosynthesis of 2,3,5,4'-tetrahydroxy stilbene-2-O-ß-D-glucoside. Gene. 2014;547(1):126-35.

43. Coassini Lokar L, Moneghini M. Geographical variation in the monoterpenes of Valeriana officinalis Leaf. Biochem Syst Ecol. 1989;17(7):563-7.

44. Bicchi C, Sandra P, Schelfaut M, Verzele M. Studies on the essential oil of Valeriana celtica L. J High Resolut Chromatogr. 1983;6(4):213-5.

45. Tzakou O, Couladis M, Pavlovic M, Soković M. Composition and antifungal activity of the oil from aerial parts and rhizomes of Valeriana dioscoridis from Greece. J Essent Oil Res. 2004;16(5):500-3.

46. Wang Y, Jin L, Yu S, Shi Q, Gu Y, Kiyota H. Chemical constituents of plants from the genus Valeriana. Mini-Reviews in Organic Chemistry. 2010;7(2):161-72.

47. Chen $H, X u X$, Zhao V. Chemical constituents of essential oil from roots and rhizomes of Valeriana alernifolia Bunge. Zhongguo Zhong Yao Za Zhi. 1998; 23(7):418-9. 447. 
48. Tuan PA, Park NI, Park WT, Kim YB, Kim JK, Lee J, Lee S-h, Yang T-J, Park SU. Carotenoids accumulation and expression of carotenogenesis genes during seedling and leaf development in Chinese cabbage ('Brassica rapa subsp. pekinensis'). 2012

49. Tuan PA, Kim JK, Park NI, Lee SY, Park SU. Carotenoid content and expression of phytoene synthase and phytoene desaturase genes in bitter melon (Momordica charantia). Food Chem. 2011;126(4):1686-92.

50. Navarrete A, Avula B, Choi Y-W, Khan IA. Chemical fingerprinting of valeriana species: simultaneous determination of valerenic acids, flavonoids, and phenylpropanoids using liquid chromatography with ultraviolet detection. J AOAC Int. 2006;89(1):8-15.

51. Tang Y-P, Liu X, Yu B. Two new flavone glycosides from Valeriana jatamansi. J Asian Nat Prod Res. 2003;5(4):257-61.

52. Bhatt ID, Dauthal P, Rawat S, Gaira KS, Jugran A, Rawal RS, Dhar U. Characterization of essential oil composition, phenolic content, and antioxidant properties in wild and planted individuals of Valeriana jatamansi Jones. Sci Hortic. 2012;136:61-8.

53. Yamazaki M, Mochida K, Asano T, Nakabayashi R, Chiba M, Udomson N, Yamazaki Y, Goodenowe DB, Sankawa U, Yoshida T. Coupling deep transcriptome analysis with untargeted metabolic profiling in Ophiorrhiza pumila to further the understanding of the biosynthesis of the anti-cancer alkaloid camptothecin and anthraquinones. Plant Cell Physiol. 2013;54(5): 686-96.

54. Lee JM, Joung JG, McQuinn R, Chung MY, Fei Z, Tieman D, Klee H, Giovannoni J. Combined transcriptome, genetic diversity and metabolite profiling in tomato fruit reveals that the ethylene response factor SIERF6 plays an important role in ripening and carotenoid accumulation. The Plant Journal. 2012;70(2):191-204.

55. Temnykh S, DeClerck G, Lukashova A, Lipovich L, Cartinhour S, McCouch S Computational and Experimental Analysis of Microsatellites in Rice (Oryza sativa L.): Frequency, Length Variation, Transposon Associations, and Genetic Marker Potential. Genome Res. 2001;11(8):1441-52.

56. Huang X, Madan A. CAP3: A DNA Sequence Assembly Program. Genome Res. 1999;9(9):868-77.

57. Ye J, Fang L, Zheng H, Zhang Y, Chen J, Zhang Z, Wang J, Shengting Li, Ruiqiang Li, Bolund L et al. WEGO: a web tool for plotting GO annotations. Nucleic Acids Res. 2006;34:293-7.

58. Mortazavi A, Williams BA, McCue K, Schaeffer L, Wold B. Mapping and quantifying mammalian transcriptomes by RNA-Seq. Nat Methods. 2008:5:621-8.

59. Benjamini Y, Hochberg Y. Controlling the False Discovery Rate: A Practical and Powerful Approach to Multiple Testing. J R Stat Soc Ser B Methodol. 1995;57(1):289-300.

60. Kim JK, Park S-Y, Lim S-H, Yeo Y, Cho HS, Ha S-H. Comparative metabolic profiling of pigmented rice (Oryza sativa L.) cultivars reveals primary metabolites are correlated with secondary metabolites. J Cereal Sci. 2013;57(1):14-20.

\section{Submit your next manuscript to BioMed Central and we will help you at every step:}

- We accept pre-submission inquiries

- Our selector tool helps you to find the most relevant journal

- We provide round the clock customer support

- Convenient online submission

- Thorough peer review

- Inclusion in PubMed and all major indexing services

- Maximum visibility for your research

Submit your manuscript at www.biomedcentral.com/submit 